\title{
AÇÃO FÍSICA: AFETO E ÉTICA
}

\author{
Renato Ferracini ${ }^{1}$
}

\section{Resumo}

A reflexão constante no artigo parte das conhecidas conceituações sobre gesto, movimento e ação de Grotowski para desenvolver um pensamento crítico sobre os conceitos de treinamento e preparação do atuador enquanto limite ético sobre o seu fazer teatral; a memória como experiência/vivência de criação e recriação constante nessa mesma preparação além do desenvolvimento da definição do atuador enquanto porosidade de afetos antes de ser um fazedor de ações.

Palavras-chave: ação, preparação, memória.

\begin{abstract}
The reflection in the article leaves of the acquaintances conceptions about gesture, movement and action of Grotowski to develop a critical thought about concepts of the training and preparation of the performer while it limits ethical on yours to do theatrical; the memory as creation experience / existence and constant creation in that same preparation besides the development of the definition of the performer while porosity of affections before being a maker of actions.
\end{abstract}

Keywords: action, preparation, memory.

\section{[...] somos um grau de potência, definido pelo poder} de afetar e ser afetado. Mas jamais sabemos de antemão qual é nossa potência. Do que somos capazes. É sempre uma questão de experimentação. Não sabemos ainda o que pode o corpo, diz Espinosa, só o descobriremos no decorrer da existência. Ao sabor dos encontros. Só através de encontros aprendemos a selecionar o que convém com nosso corpo, o que não convém, o que com ele se compõe, o que tende a decompô-lo, o que aumenta sua força de existir, o que a diminui, o que aumenta sua potência de agir, o que a diminui. Peter Pal Pelbart ${ }^{2}$

Já é bastante comum a conceituação de ação física designada por Grotowski e Thomas Richards. Partindo da diferença entre atividade, gesto e movimento, podemos iniciar uma discussão conceitual sobre o que vem a ser ação física no território da atuação.
${ }^{1}$ Renato Ferracini é doutor (2004) em

Multimeios pela UNI-

CAMP. É ator-pesquisador colaborador do LUME - Núcleo interdisciplinar de Pesquisas Teatrais da UNICAMP e atua teórica e praticamente em todas as linhas de pesquisa do núcleo desde 0 ano de 1993.

Atualmente é professor e orientador da pós-graduação em Artes da UNICAMP e ministrou aulas na pós-graduação - como professor convidado - na USP, UFPB (especialização), FURB (especialização) e Universidade de Évora (Portugal). Coordenou o projeto Jovem-Pesquisador da FAPESP "Aspectos Orgânicos na Dramaturgia de Ator": um projeto inter institucional entre LUME UNICAMP - LINCE USP. Atualmente é vice-coordenador do GT Territórios e Fronteiras da ABRACE.

${ }^{2}$ In Saadi e Garcia (ORG), 2008, p. 33. 
${ }^{3}$ Palestra proferida por Grotowski no Festival de Teatro de Santo Arcângelo (Itália), em junho de 1988. Texto completo e traduzido pode ser encontrado no http://www. grupotempo.com.br/ tex_grot.html, acesso dia 23/07/2009 às $11: 47$.
Diferença entre atividade e ação:

As atividades no sentido de limpar o chão, lavar pratos, fumar cachimbo não são ações físicas, são atividades. Pessoas que pensam trabalhar sobre o método das ações físicas fazem sempre esta confusão. Muito freqüentemente o diretor que diz trabalhar segundo as ações físicas manda lavar pratos e chão. Mas uma atividade pode se transformar em ação física. Por exemplo, se vocês me colocarem uma pergunta muito embaraçosa (e é quase sempre assim), eu tenho de ganhar tempo. Começo então a preparar meu cachimbo de maneira muito "sólida". Neste momento vira ação física, porque isto me serve. Estou muito ocupado em preparar o cachimbo, acender o fogo, assim depois posso responder à pergunta (GROTOWSKI, 1988) .

Diferença entre gesto e ação:

Outra confusão relativa às ações físicas: é de que são gestos. Os atores normalmente fazem muitos gestos pensando que este é o "métier". Existem gestos profissionais - como os do padre. Sempre assim muito sacramentais. Isto são gestos, não ações.(...)

O que é um gesto se olharmos do exterior? Como reconhecê-lo? O gesto é uma ação periférica do corpo, não nasce do interno do corpo, mas da periferia. $1^{\circ}$ exemplo: quando os fazendeiros dizem um bom dia às visitas, se são ainda ligados à vida tradicional, o movimento da mão começa dentro do corpo (Grotowski demonstra), e os da cidade assim (demonstra o mesmo movimento partindo das mãos.). Este é o gesto. Quase sempre se encontra na periferia, nas "caras", nesta parte das mãos, nos pés, pois muito freqüentemente não tem origem na coluna vertebral. Ao contrário a ação é algo mais, porque nasce do interno do corpo, está radicada na coluna vertebral e habita o corpo (idem, ibdem).

Diferença entre movimento e ação:

Outra confusão é entre movimento e ação. O movimento como na coreografia, não é ação física. Mas cada ação física pode ser colocada em forma, em ritmo, pode vir a ser, mesmo a mais simples, uma estrutura, uma partícula de interpretação perfeitamente estruturada, organizada, ritmada. Do externo, nos dois casos, estamos diante de uma coreografia. Mas no primeiro caso, coreografia é somente movimento e no segundo é o externo de um ciclo de ações intencionais. Quer dizer que no segundo caso, a coreografia é parida no fim, como a estruturação de reações na vida (idem, ibidem). 
Assim, podemos arriscar, por meio dessas citações um inicio de conceituação. Ação física é algo que:

01) Necessita de elementos básicos como concentração, objetivo e um vínculo com alguma outra imagem ou necessidade externa à atividade desenvolvida: "Neste momento vira ação física, porque isto me serve. Estou muito ocupado em preparar o cachimbo, acender o fogo, assim depois posso responder à pergunta”. Ação física, nesse contexto é algo que ocorre no espaço "entre" uma atividade e uma conexão externa a essa mesma atividade.

02) Não nasce na periferia do corpo. Uma ação física sempre é um engajamento muscular e nervoso total. "Ao contrário a ação é algo mais, porque nasce do interno do corpo, está radicada na coluna vertebral e habita o corpo"

03) A ação física deve ser organizada, formalizada, ritmada. Mas não é o movimento que é organizado. Essa organização e seu ritmo devem partir de um corpo ao realizar uma ação em conexão em algo externo e com engajamento psicofísico total. "Mas cada ação física pode ser colocada em forma, em ritmo, pode vir a ser, mesmo a mais simples, uma estrutura, uma partícula de interpretação perfeitamente estruturada, organizada, ritmada."

Temos então um primeiro esboço conceitual de ação física: um fluxo muscular-nervoso com total engajamento psicofísico em conexão ou com algo externo (seja objeto, espaço, outro corpo (ator ou espectador), imagem, e mesmo outra ação física) e que é formalizada, estruturada, ritmada, enfim, codificada no tempo-espaço.

O mais importante, a nosso ver, nesse primeiro esboço conceitual, é essa "ligação" ou conexão com algo externo. A conseqüência natural desse pensamento é dizer que uma ação física nunca é em si, ou conectada com algum universo interno, essencial, "humano", mas sempre é uma relação. A ação física é relacional. A suposta "humanidade" e presença percebidas em uma ação física constroem-se nessa relação. Ela não mergulha em um suposto interior emocional do ator, ou se conecta com alguma essência humana profunda e interna. Muito pelo contrário, a ação física se conecta com o fora, ela é um corpo integrado - e por isso relaciona todo seu universo "interno" em fluxo - e projeta esse fluxo na relação com o mundo.

A ação física se territorializa em um corpo que exige essa preparação para o externo, ou seja, essa coexistência de projeção e porosidade em relação ao externo. A ação física exige um corpo-em-arte e mais, um corpo-em-arte preparado. Podemos pensar que a ação física é esse próprio corpo-em-arte 
no seu encontro de ampliação de potência. Em outras palavras: ao pensar o corpo como uma singularidade que amplia sua potência nos encontros com outras singularidades externas (o outro ou outros) e ao verificar que uma ação física relaciona essas singularidades ou proporciona esses encontros podemos dizer que as bordas e fronteiras entre um suposto interno e um suposto externo se diluem na própria ação física. Ela - a ação - se projeta para fora ao mesmo tempo em que esse fora afetado, atinge e afeta ela mesma. A esse movimento em fluxo espiralado de diferenciação da ação física, a esse diluídoprojetado de sujeito e objeto dei o nome de corpo-subjétil. Esse corpo-subjétil produz essas "ações físicas" que nada mais são que territórios complexos e precisos (sempre em desterritorialização) cujo fluxo de produção se entende por - concomitantemente - gerar e afetar o próprio território que produz, diferenciando-o e recriando-o em continuum. No LUME chamamos a ação física de matriz. Se o corpo-subjétil é fluxo de diferenciação em projeção enquanto conceito, a matriz é seu território enquanto um conjunto de práticas operativas e qualitativas tanto no nível atual macroscópico das percepções e materialidades precisas como também nas zonas de micropercepções energéticas e de forças virtuais produzidas no encontro com o outro (ou outros) em ampliação de potência. A matriz é o correspondente cênico da Alegria de Espinosa.

Importante observar que a matriz (ação física) amplia sua potência no encontro. Já dissemos que a matriz acontece no espaço "entre" uma atividade e uma conexão externa a essa mesma atividade. Assim, essa atividade ou singularidade externa deve afetar a matriz para que o encontro ocorra em acontecimento presente e aconteça o fluxo de diferenciação. Podemos dizer que a capacidade de afeto de uma matriz determina sua própria potência. É o afeto e não a ação consciente do movimento que produz a potência da matriz. Quanto mais porosa a matriz, mas potente ela será. Uma porosidade microscópica criada na própria ação atual macroscópica. Convém dizer que essa capacidade de afeto, ou porosidade, não é, em absoluto, a capacidade de diferenciação macroscópica, mas microscópica, pois essa porosidade encontrase nos interstícios da precisão do movimento, nos espaços entre a plasticidade desenhada da ação e na capacidade desse desenho projetar-se. Dessa forma, a capacidade de afetar-se pelo mundo e não a capacidade de atuação consciente nele é o que define a potência da matriz. É a capacidade de afetar-se, de ser porosa, que faz com que a matriz inicie seu processo de fluxo de diferenciação ativa e passiva coexistente, e não sua ação ativa consciente no espaço.

Ora, essa capacidade de organicidade da matriz discutida acima é a mesma capacidade do corpo enquanto poder de existência relacionada à sua capacidade de afeto e não de poder de agir - e esse "poder" pode ser entendido aqui como aquilo que o corpo pode fazer. 
Deleuze nos lembra que a investigação dessa estrutura não deve ser em termos de poder de agir (espontaneidade) mas sim em termos de poder de ser afetado: "a estrutura de um corpo é a composição de sua relação. Aquilo que um corpo pode fazer é tanto a natureza quanto os limites de seu poder de ser afetado. O horizonte de afetividade, então, propiciará o terreno para a nossa especulação e revelará outras distinções dentro do corpo, distinções dentro do poder (HARDT, 1996 , p. 148).

A potência de existência do corpo relaciona-se - mesmo em seu estado cotidiano de existência - mais com o seu poder de ser afetado e de compor com as forças externas para ampliar sua potência do que pelo seu poder e sua capacidade de agir. No corpo, assim como na matriz poética, o agir se produz pelo afeto. A preparação do ator deveria focar seu trabalho muito mais em sua capacidade e em seu poder de ser afetado do que em seu poder de afetar. É por isso que a pretensa intenção do atuador de "atingir o público" com sua ação parte de uma premissa equivocada. $\mathrm{O}$ ator busca ser afetado pelo mundo ao seu redor para, com isso e por meio disso, agir diferenciando-se em suas micro-ações. Esse poder de ser afetado também não deve ser confundido como causa-efeito: o atuador não se afeta para depois agir. Ele, em realidade, age com o afeto, no afeto, pelo afeto.

Mas o ator age. Essa é sua função: agir, fazer ações orgânicas. O ator é um fazedor profissional de ações orgânicas. A ação física é sua poesia cênica. (Burnier). Mas essa ação deveria ser justamente a mediação, a intersecção, a relação biunívoca e bitransitiva entre pontas que se dobram: o afeto e o agir. A ação deita no afeto que alimenta o próprio afeto e o diferencia em sua micropercepção que, por estar diferenciado, re-produz outra ação pelo afeto micro-diferenciado. Espinosa chama de conatus essa intersecção entre afeto-ação. Conatus poderia ser traduzido por esforço (segundo Hardt) o que nos dá uma noção de produção, experimentação, empenho de execução, comprometimento de práticas.

[O Conatus] por um lado, é a essência do ser na medida em que o ser é produtivo; é o motor que anima o ser como o mundo. Nesse sentido, conatus é a continuação, em Espinosa, do legado do naturalismo da renascença: o ser é espontaneidade, pura atividade. Por outro lado, entretanto, o conatus é também a instância do princípio ontológico de poder, dado que o conatus é uma sensibilidade; é movido não apenas pelas ações mas também pelas paixões da mente e do corpo. É essa rica síntese da espontaneidade e da afetividade que marca a continuidade entre o princípio ontológico de poder e o conatus (HARDT, 1996, p. 150). 
Buscar esse conatus ético de Espinosa na vida e na potência cotidiana do corpo pode ser traduzido poeticamente com o que chamamos de treinamento ou ainda, o que prefiro chamar no momento, de preparação: preparação do atuador enquanto busca desse ponto de convergência dinâmica: deixar-se afetar e agir. Treinamento ou preparação como conatus poético do atuador. Eugênio Barba chama esse território de busca de pré-expressividade. E ler esse conceito da antropologia teatral como um conceito de ação não expressiva, ou ainda, ação antes da expressão é um erro. O corpo expressa. O corpo cotidiano expressa sempre. Mesmo o suposto vazio e a inação são uma forma de específica de expressão. Mas podemos dizer que as expressões cotidianas são varridas por um coletivo múltiplo de gestuais lugares-comuns. Clichês e sensos comuns corpóreos regem as expressões cotidianas, sejam elas coletivas ou singulares. Podemos arriscar que essas ações-clichês sejam o agir espontâneo ou mecânico sem o tempo do afeto. É dessa forma que o clichê corpóreo poderia ser definido como uma ação mecânica, um agir espontâneo cotidiano sem o tempo do afetarse. Isso obviamente não é uma crítica nem individual nem social. Esses gestuais clichês e sensos comuns nos permitem a comunicação do dia-a-dia e, portanto, são necessários a uma época, cultura e a singularidades inseridas nesse território temporal e espacial específico. Mauss e Le-Breton possuem estudos profundos nesse sentido. Mas a arte corporal, o corpo-subjétil busca a transgressão desses limites expressivos cotidianos. E para isso ele precisa de preparação e da busca dessa síntese que o conatus de Espinosa propõe: deixar-se afetar e agir.

Preparar um corpo-subjétil é buscar ir além dessa géstica cotidiana. Treinar e preparar o corpo pré-expressivamente é o mesmo que realizar uma pós-expressão cotidiana, pós no sentido de novas possibilidades, póspossibilidades. Buscar potências de possibilidades; levar o corpo em uma jornada de possíveis: isso é pré-expressividade e não há nada mais expressivo que a pré-expressividade. Para se lançar nesse território pré-pós-expressivo (portanto entre) o corpo necessita de um território cujo tempo e espaço possam ser dobrados, reconfigurados e cuja potência de ação possa ser alegre no sentido espinosano de aumento de potência. É dessa necessidade que vem a palavra treinamento. Mas cada ator, cada grupo, cada corpo-subjétil constrói o seu próprio treinar e treinar esse corpo-subjétil não é tão somente um trabalho necessariamente realizado em sala por um período determinado de tempo. O treinar é uma busca de estado de tempos de afetar-se; e não exercícios executados em um espaço-tempo exato em um agir mecânico. No estado do treinar, pouco importa a execução precisa e exata do exercício ou sua evolução enquanto complexidade. Importa, sim, o uso de trabalhos e exercícios para se atingir um limite, uma borda, criar uma fissura em sua géstica conhecida e cotidiana ou mesmo em seus clichês expressivos artísticos singulares no caso de um ator com experiência. 
Esse treinar - quase uma ética - essa pré-pós-expressividade está alicerçada em três pilares básicos que são três multiplicidades complexas e que se comunicam em rizoma: a memória, a vivência e a experiência.

A memória é duração. A memória virtualiza o passado em um presente que sempre passa. Mas o passado virtual não se traduz por arquivos acumulados em formas de lembranças concretas, mas precipita-se em uma duração virtualizada que se in-corpora independentemente de nossa vontade e gera uma espécie de memória ontológica ou ainda uma memória em duração corpórea. Estamos sempre atualizando esses virtuais e essa duração sempre pressiona a própria atualização. Essa atualização pode ser meramente mecânica: quando dirigimos um carro, por exemplo, atualizamos mecanicamente os virtuais de memória do coletivo de ações do guiar ou essas memórias são atualizadas independentes de nossa vontade: um cheiro que nos remete a uma atualização de sensação como um gosto que atualiza uma memória involuntária: Proust, em "Em Busca do Tempo Perdido" poetiza magnificamente essa potência independente de atualização de memória em sua passagem sobre o gosto do bolinho de Madeleine, lembrança da infância do herói, na cidade de Combray, atualizada pelo gosto do bolinho com chá (2006, p. 69-74). Mas a ação de atualização não é uma ida do presente ao passado em uma espécie de re-vivência da lembrança, mas uma atualização é uma vinda do passado ao presente que gera uma recriação da lembrança enquanto potência virtualizada no aqui agora. É por isso que toda atualização é uma criação: a vinda do passado ao presente recria a passado nesse mesmo presente.

Acredito que haja uma espécie bem específica de atualização de memória que é a sua atualização corpórea para um fim estético. Estamos falando, agora, da capacidade do atuador em buscar uma atualização dessa virtualidade de memória, recriando-a em um fluxo corpóreo poético, ou ainda, a capacidade do atuador em atualizar uma ação poética da mesma forma como as palavras de Proust em sua passagem magnífica da Madeleine. Mas a atualização do atuador - ao invés de serem palavras e frases de uma literatura em suas seqüencias, ritmos e cores - é realizada por meio de ações físicas ou matrizes corpóreas. Atualização de vivências e experiências com o corpo, pelo corpo, através do corpo. Esse movimento, esse fluxo é possível devido à atualização de vivências intensivas trabalhadas em estado de treinamento ou preparação.

Vivência deve ser entendida aqui como algo que:

[...] étrazida para fora da continuidade da vida, permanecendo ao mesmo tempo referida ao todo da própria vida.[...] Na medida que a vivência fica integrada ao todo da vida, este todo se torna também presente nela (GADAMER, 2006, p. 116). 
Segundo Gadamer, uma vivência teria a capacidade de, ao mesmo tempo, realizar certo desvio de fluxo da vida, mantendo nesse mesmo desvio o todo potente da própria vida; e esse desvio vital - que contém o todo da vida - faz parte da própria vida. Uma vivência, nesse caso, é uma experiência intensiva, vital, lançada de forma potente na duração virtual de memória e que mantém o todo da potência vital dentro dela mesma. Vivência enquanto metonímia de potência. Em outras palavras: vivenciamos experiências que são lançados como virtuais potentes de memória. Esses virtuais contêm, em si, todo o potencial da própria vida: parte e todo como um só rizoma. Esses virtuais de vivência intensiva, que podemos chamar de nódulos de potência virtuais, são potencialidades virtuais a serem atualizados no momento do estado cênico. É quando atualizadas em fluxo de re-criação que podemos chamar esses nódulos de matrizes. Treinar, portanto, significa criar a possibilidade de vivenciar experiências intensivas, a ponto de essas experiências serem passíveis de recriação posterior, recriando seu fluxo vital que ela, em si, já contém. Assim, a questão não é executar um trabalho, mas vivenciá-lo, experiência-lo, puxar esse trabalho em um limite intensivo. Claro que não estou falando aqui de um elemento meramente mental no sentido de uma lembrança racional, mas essa vivência como virtualidade potente no próprio corpo-memória, ou seja, não devemos entender memória e vivência como experiências mentais ou meramente imagéticas, localizadas em um ponto específico chamado cérebro, mas devemos entender essas vivências como vivências corpóreas, vivências-subjéteis. Será que ainda necessitamos provar o corpo integrado? Memória é corpo, já gritavam tantos pesquisadores teatrais. Continuemos a gritar, então...

Mas a vivência vem pela experiência da preparação e do treinar. $\mathrm{E}$ aqui voltamos ao poder de se deixar afetar e não somente de agir. Gerar vivências está mais para deixar-se afetar do que agir; e o mesmo ocorre com a busca do limite. Preparar-se é parar, ouvir, deixa-se impregnar pelo espaço e pelo tempo. Deixar-se penetrar pelo outro e pelo mundo. Ser afetado por você mesmo. Experiênciar é gerar vivências nas micropercepções de espaço-tempo e nas microrelações com o outro. Treinar é buscar vivências e linhas de fuga com a recomposição do encontro com suas próprias linhas de força e com as linhas de força que se compõe nos encontros. Segundo Larrosa, a experiência não está no tempo de vida ou profissional, nem no acumulo de opiniões referendadas; não se assenta no conhecimento científico ou artístico, nem no mundo conceitual das definições nem mesmo no acumulo de informações. A experiência não mora na velocidade, mas no tempo dilatado. No afeto:

A experiência, a possibilidade de que algo nos aconteça ou nos toque, requer um gesto de interrupção, um gesto que é quase impossivel nos tempos que correm: requer parar para pensar, parar para olhar, 
parar para escutar, pensar mais devagar, olhar mais devagar, e escutar mais devagar; parar para sentir, sentir mais devagar, demorar-se nos detalhes, suspender a opinião, suspender o juizo, suspender a vontade, suspender o automatismo da ação, cultivar a atenção e a delicadeza, abrir os olhos e os ouvidos, falar sobre o que nos acontece, aprender a lentidão, escutar aos outros, cultivar a arte do encontro, calar muito, ter paciência e dar-se tempo e espaço. Até aqui, a experiência e a destruição da experiência. Vamos agora ao sujeito da experiência. Esse sujeito que não é o sujeito da informação, da opinião, do trabalho, que não é o sujeito do saber, do julgar, do fazer, do poder, do querer. Se escutarmos em espanhol, nessa língua em que a experiência é "o que nos passa", o sujeito da experiência seria algo como um território de passagem, algo como uma superfície sensivel que aquilo que acontece afeta de algum modo, produz alguns afetos, inscreve algumas marcas, deixa alguns vestígios, alguns efeitos. Se escutamos em francês, em que a experiência é "ce que nous arrive", o sujeito da experiência é um ponto de chegada, um lugar a que chegam as coisas, como um lugar que recebe o que chega e que, ao receber, lhe dá lugar. E em português, em italiano e em inglês, em que a experiência soa como "aquilo que nos acontece, nos sucede", ou "happen to us", o sujeito da experiência é sobretudo um espaço onde têm lugar os acontecimentos (LARROSA, 2002, p.19).

Ou ainda, Larrosa, citando Heidegger:

[...] fazer uma experiência com algo significa que algo nos acontece, nos alcança; que se apodera de nós, que nos tomba e nos transforma. Quando falamos em "fazer" uma experiência, isso não significa precisamente que nós a façamos acontecer, "fazer" significa aqui: sofrer, padecer, tomar o que nos alcança receptivamente, aceitar, à medida que nos submetemos a algo. Fazer uma experiência quer dizer, portanto, deixar-nos abordar em nós próprios pelo que nos interpela, entrando e submetendo-nos a isso. Podemos ser assim transformados por tais experiências, de um dia para o outro ou no transcurso do tempo (HEIDEGGER apud LARROSA, 2002, p. 25).

A experiência é o tempo do afeto e também o tempo de afetarse. A experiência, portanto, não produz ação, mas produz vivências que escapam ao mundo cotidiano da opinião e das doxas. A experiência precisa de um espaço de desaceleração, de percepção e micropercepção do mundo. A experiência dobra o fluxo da vida comum e com o afeto, produz um nódulo, um aglomerado um desvio potente de vida que mantém a potência da vida como um todo (vivência cf. Gadamer). 
Experiênciar, portanto, é agir pelo poder do afeto que gera uma vivência intensiva que por sua vez se virtualiza em memória e que, em processo de atualização, produz o território do que chamamos de ação física ou matriz. Essa pode ser recriada em fluxo de diferenciação que afeta todo o processo recriando-o em um movimento espiralado de recriação. Dessa forma podemos esquematizar a seguinte relação em espiral das multiplicidades: memória, vivência, experiência.

O espaço-tempo de preparação gera Experiência enquanto afeto $\rightarrow$ esse afeto gera vivência enquanto desvio, nódulo parcial vital que mantém o todo potente da vida $\rightarrow$ esse desvio potente do fluxo vital comum gera memória enquanto duração virtual potente no presente do corpo $\rightarrow$ sua ação de atualização produz um território-matriz (território de recriação) macroscópico extenso corpóreo e microscópico de força e intenso mas sempre poroso para afetos e auto-afetos $\rightarrow$ a ação de atualização dessa matriz recria o território da matriz e a diferencia em seu universo de micropercepção $\rightarrow$ Essa micro-diferenciação no território-matriz, em função de sua porosidade, gera nele mesmo uma experiência interna ao território-matriz $\rightarrow$ esse auto-afeto gera um nódulo de potência e por conseguinte produz uma vivência interna ao próprio território da matriz desterritorializando-a e reterritorializando-a nela mesma $\rightarrow$ Essa vivência re-atuliza a memória do território-matriz $\rightarrow$ Essa re-atualização gera nova experiência que gera nova vivência $\rightarrow$ e assim numa espiral contínua de recriação microscópicas no território matriz $\rightarrow$ Esse movimento gera a eterna presentificação do território-matriz ou da ação física pois a matriz dilui-se em sua porosidade, mas mantém sua macroscopia de precisão e de plasticidade.

Podemos chamar esse esquema de fluxo de diferenciação da matriz de precisão afetiva. Essa contém em seu conjunto relacional a precisão plástica da macroação da matriz, mas jamais pode se reduzir a ela. É justamente esse fluxo de precisão afetiva que lança a ação mecânica na sensação.

Dessa forma, por meio do afeto, e não da ação consciente no espaço-tempo e da precisão de sua mecanicidade, ampliamos o conceito de "treinamento": um "treinar" pode estar inserido na ação de, por exemplo, sair às ruas e vivenciar experiências, observar os fluxos cotidianos, olhar as relações sociais a ponto de gerar um afeto, uma experiência e uma vivência intensiva. Um ensaio pode ser um estado de trabalho constante na busca de experiências e suas vivências e, é claro, o próprio estado cênico se configura como uma fonte constante de experimentação. O território do "treinar" é muito mais amplo que um espaço-tempo destinado à realização de exercícios mecânicos ou busca de precisão plástica. O "treinar" se configura muito mais como uma postura ética na relação com o corpo, com o espaço, com as relações 
sociais, com suas próprias singularidades. Um atuador deve estar em constante treinamento ou, em outras palavras: um performador deve estar na busca constante de fissurar seus limites de ação procurando uma potência possível de expressão, seja em uma sala de trabalho, seja no ensaio de um espetáculo, seja dentro do próprio espetáculo, seja em um happening ou uma performance. No espetáculo e na ação performática se treina, assim como no cotidiano pode se encontrar estados cênicos. O importante é encontrar potências de experiências que produzem vivências e que em si mesmas mantêm sua força vital: experiência como força motriz que lançadas como virtuais potentes na memória dos atuadores serão sua fonte inesgotável de organicidade e vida em toda sua força de diferenciação.

\section{Referências bibliográficas}

GADAMER, Hans-Gerog. Verdade e Método I. Traços fundamentais de uma hermenêutica filosófica. Trad. Flávio Paulo Meurer. Petrópolis, RJ: Vozes, Bragança Paulista: SP, Editora Universitária São Francisco, 2005.

HARDT, Michel. Gilles Deleuze - Um aprendizado em filosofia. Trad Sueli Cavendish. São Paulo: Editora 34, 1993.

LARROSA, Joge Bondia. Notas sobre a experiência e o Saber de Experiência. Trad. João Wanderley Geraldi. Revista Brasileira de Educação, Campinas, v. 1, n. 19, 20 a 28. Abril de 2002.

PROUST, Marcel. Em busca do Tempo Perdido. v. 1. No caminho de Swann. Trad. Mario Quintana. São Paulo: Globo, 2006.

SAAD, Fátima; GARCIA, Silvana (org.). Próximo Ato: Questões da Teatralidade Contemporânea. São Paulo: Itaú Cultural, 2006. 